\title{
Challenges in All-DC Offshore Wind Power Plants
}

\author{
Alessandra Follo ${ }^{1,2, * \mathbb{D}}$, Oscar Saborío-Romano ${ }^{1} \mathbb{D}$, Elisabetta Tedeschi ${ }^{2,3}{ }^{\mathbb{D}}$ and Nicolaos A. Cutululis ${ }^{1} \mathbb{D}$ \\ 1 Department of Wind Energy, Technical University of Denmark, 4000 Roskilde, Denmark; \\ osro@dtu.dk (O.S.-R.); niac@dtu.dk (N.A.C.) \\ 2 Department of Electric Power Engineering, Norwegian University of Science and Technology, \\ 7491 Trondheim, Norway; elisabetta.tedeschi@ntnu.no \\ 3 Department of Industrial Engineering, University of Trento, 38123 Povo, Italy \\ * Correspondence: afollo@dtu.dk
}

Citation: Follo, A.; Saborío-Romano, O.; Tedeschi, E.; Cutululis, N.A. Challenges in All-DC Offshore Wind Power Plants. Energies 2021, 14, 6057. https://doi.org/10.3390/en14196057

Academic Editor: Miguel-Angel Tarancon

Received: 6 May 2021

Accepted: 13 September 2021

Published: 23 September 2021

Publisher's Note: MDPI stays neutral with regard to jurisdictional claims in published maps and institutional affiliations.

Copyright: (c) 2021 by the authors. Licensee MDPI, Basel, Switzerland. This article is an open access article distributed under the terms and conditions of the Creative Commons Attribution (CC BY) license (https:/ / creativecommons.org/licenses/by/ $4.0 /)$.

\begin{abstract}
As the size and distance from shore of new offshore wind power plants (OWPPs) increase, connection to shore using high-voltage (HV) direct-current (DC) technology becomes more costeffective. Currently, every offshore wind power plant has a collection system based on mediumvoltage alternating-current technology. Such systems rely on heavy and bulky low-frequency (i.e., 50 or $60 \mathrm{~Hz}$ ) transformers: a drawback offshore, where equipment weight and space are restricted. Consequently, there is growing interest in medium-voltage direct-current collection systems, in which low-frequency transformers are replaced with DC/DC converters equipped with lighter and smaller medium-frequency transformers. However, the deployment of all-DC OWPPs still faces several challenges. Based on a very comprehensive and critical literature review, three of them are identified and discussed in this paper. The first challenge is the technological gap at component level. In this work, the DC/DC converter topologies most suitable for application to OWPPs are described and compared. The second challenge is the controllability of DC collection systems. Parallel, series and hybrid DC collection system layouts are presented and discussed. The third challenge is the compliance of all-DC OWPPs with current requirements for their connection to the onshore grids. The three challenges are discussed to highlight current research gaps and potential future directions.
\end{abstract}

Keywords: offshore wind power plant; DC collection system; DC/DC converter

\section{Introduction}

With the growing demand for electricity produced from renewable sources [1] such as wind, solar, wave and tidal, offshore wind will play a key role. The global installed capacity of offshore wind energy is forecast to almost triple between 2019 and 2024 [2,3]. Due to superior wind conditions and lower space restrictions away from cost lines, there is a clear trend towards the installation of larger, better performing wind turbines (WTs) and the deployment of larger wind power plants (WPPs) $[3,4]$.

To date, most offshore wind power plants (OWPPs) rely on high-voltage (HV) alternatingcurrent (AC) transmission systems. For large-scale OWPPs located beyond some tens of $\mathrm{km}$ from shore, HVAC transmission systems may require midpoint reactive compensation platforms, due to the high charging currents of the transmission cables [5-7]. In contrast, HV direct-current (DC) technology enables a more efficient transmission of power over long distances: with lower cable losses and dispensing with charging currents (and corresponding reactive power compensation) [6-8]. Currently, all OWPPs rely on medium-voltage (MV) AC collection systems. In such mature, widely used technology, low-frequency (i.e., 50 or $60 \mathrm{~Hz}$ ) transformers facilitate the stepping up or down of the collection system voltage.

DC collection systems offer several advantages over their MVAC counterparts. As previously mentioned for HVDC transmission, DC cables have lower losses and do not need reactive power compensation. Another advantage is the replacement of heavy and bulky low-frequency transformers with DC/DC converters equipped with lighter and smaller 
medium-frequency (e.g., $150 \mathrm{~Hz}$ ) transformers [8]. The potential reduction of size and weight is important in offshore applications, where space and supporting structures for the equipment are limited and expensive. However, the deployment of DC technology is still facing several challenges, and there are currently no operational all-DC WPPs or full-scale pilots of WPPs with DC collection systems installed [6,9-11].

Moreover, OWPPs are also required to comply with grid codes specific to the onshore grid to which they are connected. Reference [12] analyses the national grid codes of selected European countries. The grid codes [13,14] have also been developed to harmonise the national grid codes at the European level. However, grid code requirements specific to all-DC OWPPs have not been established yet [15]. Thus, the potential compliance of all-DC OWPPs with current grid code requirements (based on conventional AC OWPPs, i.e., OWPPs with MVAC collection systems) remains a topic open for discussion.

While there is a consistent body of literature dealing with DC-OWPPs, it is mostly focused on specific topics, i.e., topology or component, and does not systematically cover the whole research space aiming at identifying challenges and gaps. The main objective of this paper is to review of the current status of the research around DC collection grids for OWPPs in a critical and comprehensive manner. The aim is to provide a holistic view, addressing the DC/DC converters at component level as well as the design of the layout and control of all-DC OWPPs, and discussing the requirements for connection to the onshore grids. The findings are analysed to highlight current research gaps and indicate potential future directions. The rest of the paper is organised as follows. The current DC/DC converters topologies most suitable for medium- and high-voltage levels in OWPPs are reviewed, and technological gaps are presented in Section 2. In Section 3, different DC collection system layouts are presented, and corresponding control issues are discussed. Current grid code requirements for HVDC-connected OWPPs are examined, and possible adaptations to all-DC OWPPs are explored in Section 4. Finally, the topics presented in the previous sections are analysed in Section 5, so as to identify research gaps and propose potential future research directions, and concluding remarks are given in Section 6.

\section{Challenge I: Technological Gap in High Power DC/DC Converters}

Considerable research efforts have been directed to the study of high power DC/DC converter topologies for OWPPs. In earlier works, such as [16], and more recent ones, such as $[17,18]$, single active bridge (SAB) and LLC series-parallel resonant converter topologies were analysed. Recent studies focusing on the control of larger WPPs have also considered the dual active bridge (DAB) converter and modular multilevel converter (MMC) topologies due to their bidirectional power flow capability. The SAB, DAB and MMC converter topologies will be further analysed in this section. The structure of the topologies will be described and their advantages and disadvantages will be highlighted. Their efficiency, as well as methods to improve it, are also discussed.

DC/DC converters can be classified according to the directionality of power flow, controllability of power electronic switches and galvanic isolation of the converter.

Based on the directionality of power flow, they are classified as bi- or unidirectional. Bidirectionality of power flow is desirable in a DC/DC converter to supply loads in the OWPP with auxiliary power from the main onshore AC network when the WTs are not generating power, and to interface energy storage devices with the DC OWPP.

The second classification of DC/DC converters regards the controllability of the power electronic switches. They can be fully controllable, such as AC/DC voltage source (forced/ self-commutated) converters (VSCs). Alternatively, they can be partially controllable or non-controllable, such as AC/DC (phase-controlled) line-commutated converters (LCCs), in which the switches are arranged in a current source converter (CSC) topology. Full controllability of the switches enables independent control of active and reactive power and the capability of forming the alternating voltage on their AC terminals, i.e., regulating the voltage magnitude and angle/frequency independently, which allows the corresponding VSCs to be connected to weak/isolated AC networks. In contrast, LCCs are unidirectional 
power converters, which rely on the line voltage of the AC systems to which they are connected and are not able to form the alternating voltage on their AC terminals. Such characteristics make VSCs preferable over LCCs for connecting AC OWPPs to HVDC. LCCs (connected to strong AC networks) are however more cost-effective for transmitting large amounts of power [19].

An isolated DC/DC converter provides galvanic isolation between its terminals by means of a medium-frequency transformer, in most cases. The galvanic isolation can be imposed as a safety requirement to prevent the spread of overcurrents or overvoltages from one terminal to the other during transients, e.g., faults. Isolation allows DC/DC converters to reach higher step-up voltage ratios, while improving both efficiency and reliability [20]. The disadvantages of isolated DC/DC converters with respect to non-isolated ones are the higher costs and larger footprints.

\subsection{Single Active Bridge}

The single active bridge $(\mathrm{SAB})$, depicted in Figure 1, is a unidirectional DC/DC converter topology. It is based on an active input (i.e., lower voltage) bridge with IGBTs that provides a square wave to the medium-frequency transformer, and a passive output (i.e., higher voltage) bridge with diodes that rectifies the square wave [16].

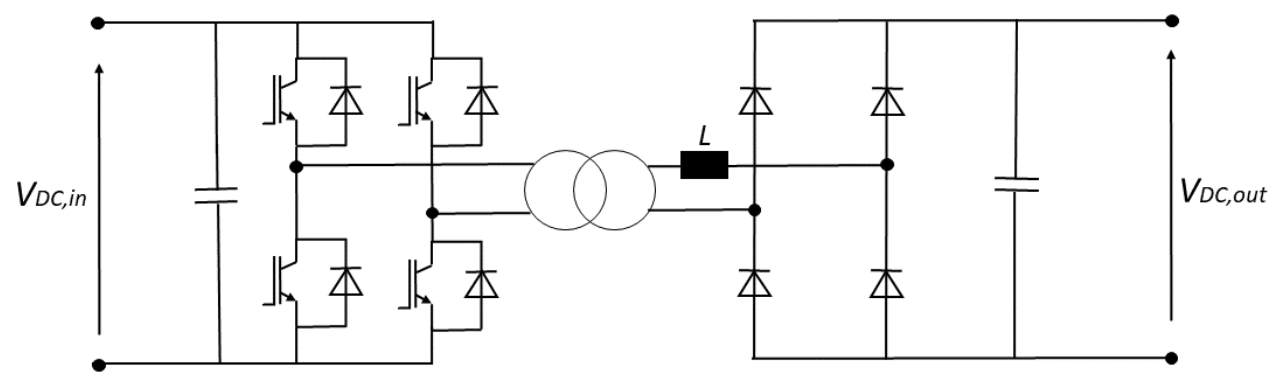

Figure 1. Single-phase single active bridge converter topology.

SAB converters are controlled either by changing their duty cycle, in discontinuous operation, or by varying the switching frequency in continuous operation. Their efficiency varies in applications requiring a wide operation ranges, since large changes in duty cycle and higher switching frequencies result in higher losses. The active switches in SAB converters are soft-switched but have a limited zero voltage switching (ZVS) range, and the rectifier diodes have high turn-off currents, leading to high losses. Since the converters must withstand high input peak currents, large number of IGBTs input modules need to be connected in parallel. However, because of the voltage-stiff output of such converters, a lower number of output (diode bridge) modules need to be connected in series [16,21].

\subsection{Dual Active Bridge}

The dual active bridge (DAB) converter topology, portrayed in Figure 2, consists of two active bridges and a medium-frequency transformer for galvanic isolation.

Bidirectionality of power flow is ensured by the use of four-quadrant switches (such as IGBTs) on both the low- and high-voltage terminals of such converters. DAB converters are suitable for MVDC applications and can achieve the required current and voltage levels with a single module or a multiple submodule structure. The multiple submodule structure consists of multiple DAB converter units connected in series or in parallel to increase voltage or current rating, respectively. The modular design facilitates scalability, and redundant modules can be inserted to improve reliability [22,23]. Other advantages of the multiple submodule structure are the possibility of keeping the medium-frequency transformer turn ratio at 1:1 to simplifying its design $[23,24]$, the easier control of voltage and current in the individual submodules and the improved thermal management of the submodules [24]. 


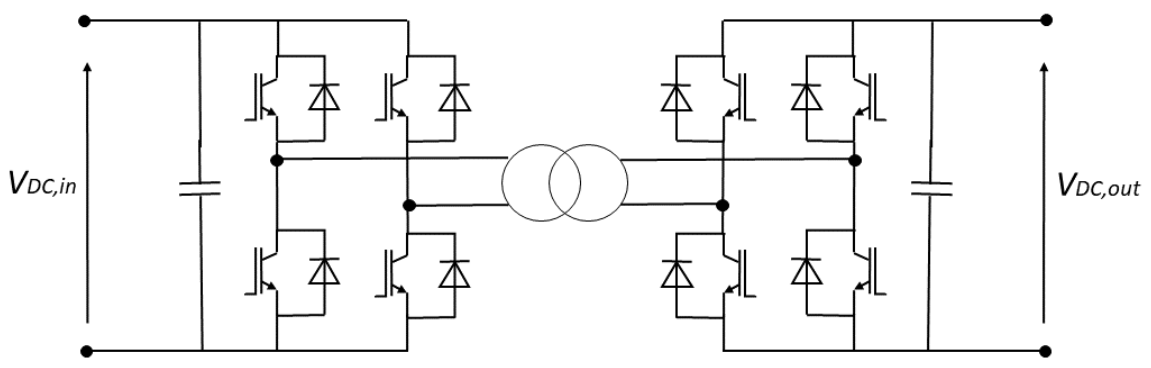

Figure 2. Single-phase dual active bridge converter topology.

$\mathrm{DAB}$ converters are designed to operate in soft-switching mode for large operation ranges, which eliminates the turn-on losses and reduces the turn-off losses. However, such switching mode is not achieved in all operation points. The bridges could become hard-switched during low loads operation or large variations of input/output voltage ratio $[25,26]$.

Nonetheless, the soft-switching operation range can be increased employing different modulation techniques or an auxiliary resonant-commutated pole [25-27].

A three-phase 5MW DAB converter was tested in a laboratory, with the results reported in [26]. The efficiency of three-phase DAB converters was claimed to reach up to $98.5 \%$ under the conditions described in [24,28]. With respect to three-phase DAB converters, single-phase DAB converters require fewer IGBTs which must withstand higher currents [24], complicating their thermal management. Three-phase DAB converters are thus probably more suitable for large-scale OWPPs than single-phase DAB converters.

\subsection{Modular Multilevel Converter}

The bidirectional DC/DC converter structure based on modular multilevel converters (MMCs) comprises a front-to-front configuration of two MMCs, one connected to the low-voltage terminals and the other one to the high-voltage terminals, with a mediumfrequency transformer for galvanic isolation, as illustrated in Figure 3. Each MMC is constructed by series connection of a large number of identical low-voltage submodules (SMs) to achieve high voltage levels.

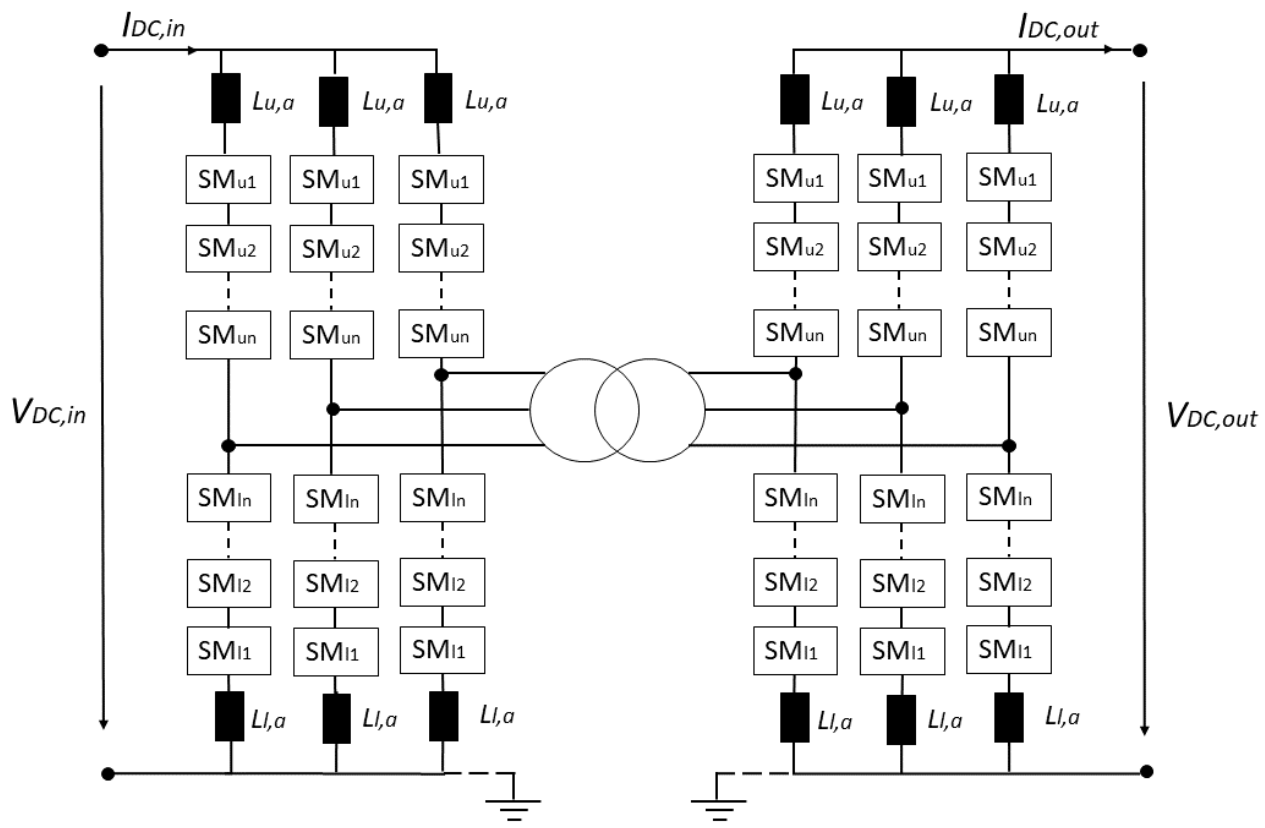

Figure 3. Isolated three-phase DC/DC converter MMC-based. 
MMCs can consist of half-bridge or full-bridge SMs, as shown in Figure 4. Half-bridge SMs can only supply a monopolar voltage, while full-bridge SMs can supply a bipolar voltage. The main advantage of the full-bridge topology is the inherent DC current blocking capability. However, the number of switches is doubled for full-bridge SMs, which may result in higher costs and switching losses [29].

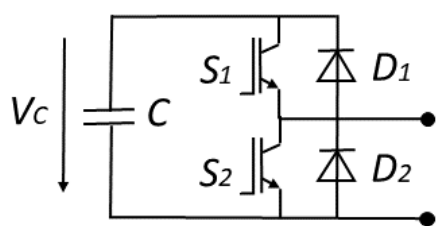

(a)

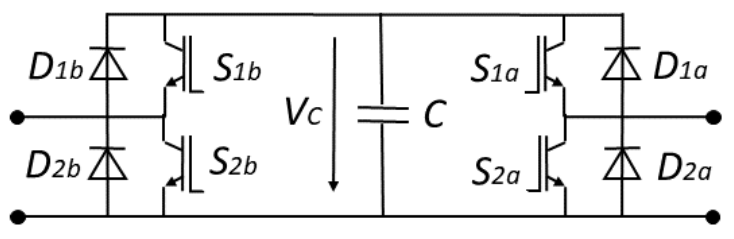

(b)

Figure 4. MMC submodules. (a) Half bridge submodule. (b) Full bridge submodule.

MMCs have become very popular for HVDC transmission due to their high modularity and scalability. Redundant SMs improve reliability, and the multilevel architecture enables low voltage and current variations across SMs, thus reducing the switching losses. The modular structure of MMCs enables the use of a single medium-frequency transformer with a turn ratio of 1:1. However, the higher number of switches required, may result in higher costs and switching losses respect to other DC/DC converter topologies. Nonetheless, the overall efficiency of a MMC-based DC/DC converter with a medium-frequency transformer may be as high as $98 \%$ [30,31].

Another drawback of MMCs regards the added complexity of the voltage balance across the SMs, and several solutions were proposed for this matter [30-32].

Different MMC converter topologies were proposed. In [33], an unidirectional version was proposed to reduce the number of SMs and increase the MMC converter efficiency. A hybrid solution combining half- and full-bridge SMs in each arm, was studied in [29]. With respect to full-bridge MMCs, hybrid MMCs ensure better use of the SMs and higher efficiency, while maintaining the DC fault blocking capability.

MMCs can also be used to control permanent magnet synchronous generators (PMSGs) in type-4 WTs at both low and high wind speeds, as proposed in [31,34].

Table 1 summarises the main advantages and disadvantages of the DC/DC converter topologies presented in this section. For each DC/DC converter topology, the main open issues and the corresponding proposed solutions are also highlighted. 
Table 1. Summary of DC/DC converter topologies presented in challenge I.

\begin{tabular}{|c|c|c|c|c|}
\hline & Advantages & Disadvantages & Relevant Open Issues & Methodologies \\
\hline SAB & High efficiency $[16,21]$. & $\begin{array}{l}\text { Limited range of high efficiency and } \\
\text { ZVS }[16,21] \text {. } \\
\text { Diode rectifiers have high turn-off } \\
\text { currents }[16,21] .\end{array}$ & & \\
\hline $\mathrm{DAB}$ & $\begin{array}{l}\text { Modularity and reliability: } \\
\text { series / parallel connection for voltage } \\
\text { levels }[22,23] \text {. } \\
\text { IGBTs in soft-switching mode for large } \\
\text { operation ranges }[25,26] \text {. }\end{array}$ & $\begin{array}{l}\text { Hard-switching of IGBTs for low loads } \\
\text { operation or large variations of input/output } \\
\text { voltage ratio }[25,26] \text {. }\end{array}$ & $\begin{array}{l}\text { IGBTs in soft-switching mode for all } \\
\text { operation ranges }[25,26] \text {. }\end{array}$ & $\begin{array}{l}\text { Increase of soft-switching } \\
\text { operation range different } \\
\text { modulation techniques [25-27]. }\end{array}$ \\
\hline \multirow[t]{3}{*}{ MMC } & $\begin{array}{l}\text { Full-bridge SMs inherent capability of } \\
\text { blocking DC current [29]. }\end{array}$ & $\begin{array}{l}\text { Full-bridge SMs twice the number of switches, } \\
\text { higher costs and switching losses [29]. }\end{array}$ & $\begin{array}{l}\text { Complexity of voltage balance across } \\
\text { the SMs [30-32]. }\end{array}$ & $\begin{array}{l}\text { A method to reduce the voltage } \\
\text { balance complexity is proposed } \\
\text { in [30-32]. }\end{array}$ \\
\hline & $\begin{array}{l}\text { Redundant SMs improve reliability, } \\
\text { the multilevel architecture reduces the } \\
\text { switching losses }[30,31] \text {. }\end{array}$ & $\begin{array}{l}\text { Higher number of switches required, higher } \\
\text { costs and switching losses }[30,31] \text {. }\end{array}$ & Increase the MMC converter efficiency. & $\begin{array}{l}\text { An unidirectional version of } \\
\text { MMC-based converter to reduce } \\
\text { the number of SMs to increase } \\
\text { the converter efficiency is } \\
\text { proposed in [33]. }\end{array}$ \\
\hline & & & $\begin{array}{l}\text { Better use of the SMs and higher } \\
\text { efficiency, while maintaining the DC } \\
\text { fault blocking capability. }\end{array}$ & $\begin{array}{l}\text { An hybrid solution combining } \\
\text { half- and full-bridge SMs in each } \\
\text { arm is proposed in [29]. }\end{array}$ \\
\hline
\end{tabular}




\section{Challenge II: Topology and Control of DC Collection Systems}

An open challenge of all-DC WPPs is the controllability of DC collection systems. HVDC is a proven transmission technology, more cost-effective than HVAC for long distances. On the other hand, MVDC technology has only been tested on laboratory-scale prototypes. Nonetheless, research work was conducted on DC collection systems $[6-10,35,36]$.

This section describes the typical topologies of DC collection systems and discusses their controllability. Such systems can be classified into three main topologies according to the connection of the WTs: parallel, series or hybrid.

The chosen configuration will influence the choice of the DC/DC converter topology, the control complexity and the overall WPP efficiency. The voltage level of the collection system also has a large impact on the efficiency and the choice of the DC/DC converter [37].

Figure 5 portrays the schematic representation of a DC OWPP. The dashed rectangle delimits the OWPP collection system, which is in the scope of this article. Intermediate platform(s) and offshore substation(s) are both topology dependent. Their role will be extensively discussed later in this section.

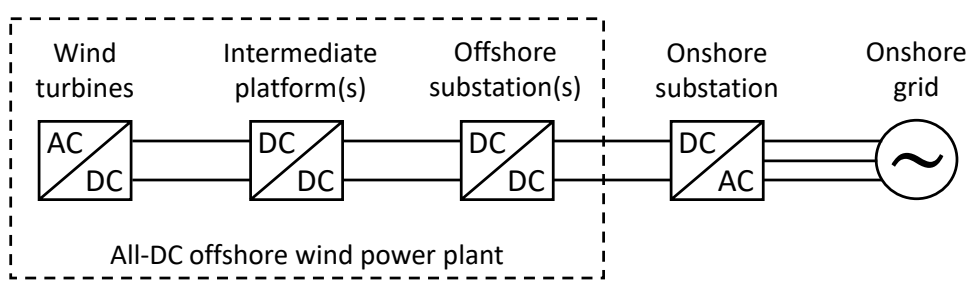

Figure 5. Schematic representation of an all-DC offshore wind power plant.

\subsection{Parallel Topologies}

In the so-called parallel topologies, each WT terminal is connected to the corresponding collection/OWPP terminal, and the total OWPP output current is the sum of the different WT output currents. Different configurations are shown in Figure 6. These topologies are the closest to AC collection systems and may thus be the natural first step in the deployment of all-DC OWPPs [38,39].

In DC collection systems with parallel-connected WTs, the voltage can be stepped up from the generation level to the transmission level in one or two stages, and in a centralised or decentralised manner, as shown in Figure 6.

The choice of configuration depends on the size of the OWPP. Large OWPPs, for example, may require two stages of conversion to reduce the power losses in the cables. The number of conversion stages depends also on the ratio between the voltage level of the collection system and the voltage level of the transmission system. If the ratio is not high, single stage configuration can be implemented, otherwise two stages of conversion will be required for power losses reduction [39].

In the two-stage voltage step-up configuration, depicted in Figure 6a, the first stage, i.e., a DC/DC converter after each WT, steps up the voltage from the generation level to the collection level. The second stage, i.e., a DC/DC converter in the offshore substation, steps up the voltage from the collection level to the transmission level. Some advantages of this configuration are the possibility of controlling the output voltage of each WT individually, which allows redundancy in the WT control, and the direct voltage step-up after each WT, which results in lower collection cable losses. Some drawbacks of the configuration are the losses and costs associated with the additional DC/DC converters [10].

In the single centralised stage configuration, shown in Figure $6 \mathrm{~b}$, the voltage is stepped up from the collection level to the transmission level by the DC/DC converter in the offshore substation. This configuration minimises the number of DC/DC converters with lower power ratings, which may result in higher overall efficiency. Since only two voltage levels are used, the generation/collection voltage level will depend on the considerably lower voltage ratings of WT generators, resulting in higher collection cable losses [10]. 


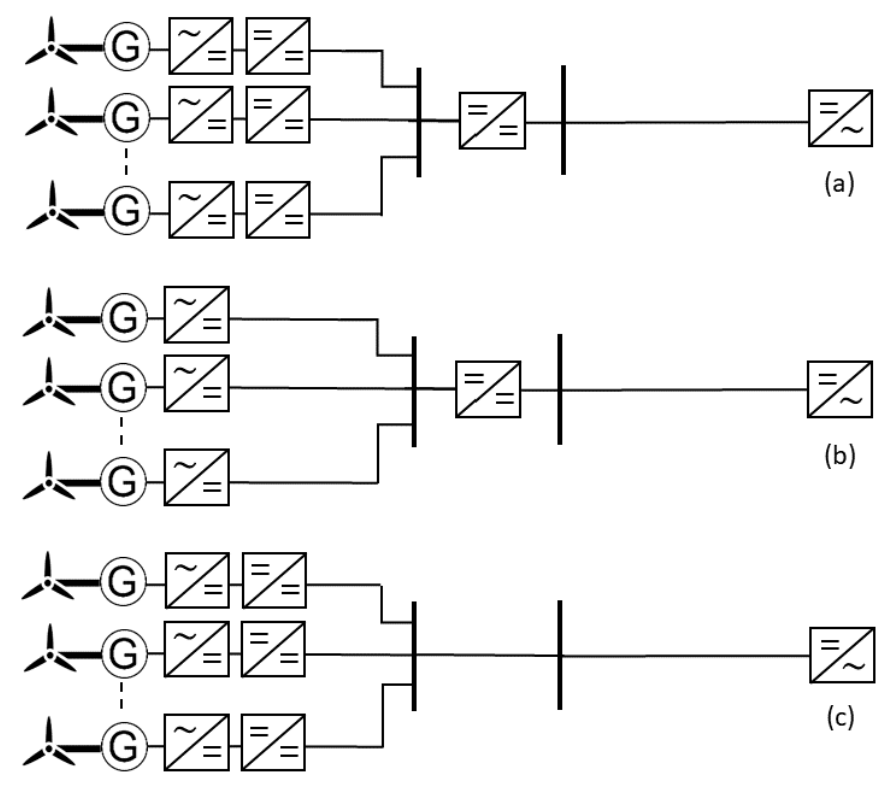

Figure 6. Different voltage step-up configurations for DC collection systems with parallel-connected WTs. (a) Two stages. (b) Single centralised stage. (c) Single decentralised stage.

In the single decentralised stage configuration, depicted in Figure $6 \mathrm{c}$, the voltage is stepped up from the generation level to the transmission level by single DC/DC converters connected directly to the WTs. In this configuration, the collection cable losses are lower because of the higher voltage, and no offshore substation is required. However, this configuration does not seem suitable for remote, large-scale OWPPs, since either the DC/DC converters must have much higher voltage conversion ratios or the power must be transmitted to shore at lower voltage levels, which results in higher transmission cable losses. Moreover, the efficiency is usually lower for such DC/DC converters of lower power ratings [10].

In the parallel connected DC collection system, each DC/DC converter needs to be controlled to provide medium and high voltage levels in the collection and transmission systems, while ensuring a proper insulation level. However, the research on DC collection systems is currently focusing on series connected DC collection systems, since the control of the voltage among the WT strings is more complicated than controlling parallel connected WTs [40].

\subsection{Series Topology}

In the series topology, shown in Figure 7, the WTs are connected in series, so that the same, relatively constant current flows through all of them and the different generationlevel WT terminal voltages build up the transmission-level OWPP voltage. The layout of DC collection systems with series-connected WTs requires less conversion stages with respect to the parallel layout, and consequently lower number of DC/DC converters, potentially resulting in higher power plant efficiency with respect to some parallel topologies $[7,39]$. The series-connected DC collection system does not require building an offshore platform since the voltage is stepped-up at the WT level.

Despite the attractive components and cost reduction, the series layout presents several technical challenges [40-43]. One of them is designing the control of series-connected DC/DC converters. When devising such controls, it was usually assumed that all WTs have (almost) the same voltage level at any point in time. However, the wind does not blow uniformly within an OWPP, and WTs experience aerodynamic interactions, which produce e.g., the wake effect. In such situations, not all WTs in the same string produce the same amount of power, and the voltage is not distributed uniformly among the WTs 
in the string. WTs with lower power output must increase their terminal voltage to keep the string terminal voltage constant. This will also happen in the case of a faulty unit in the series-connection. Consequently, the converters in the WTs need to be designed to withstand large voltage fluctuations, leading to a lower use ratio of the components. To mitigate the over-voltage challenge, reference [44] proposes the introduction of a voltage balance circuit, while reference [42] proposes an over-voltage limitation strategy carried out by the onshore high voltage converter, to ensure that the WTs are operating within a safe limit. The efficiency of the WPP can also be increased choosing the most suitable converter topology in relation to the voltage level and the grid requirements. Modulation techniques have also the potential for reducing the losses in the collection system [44].

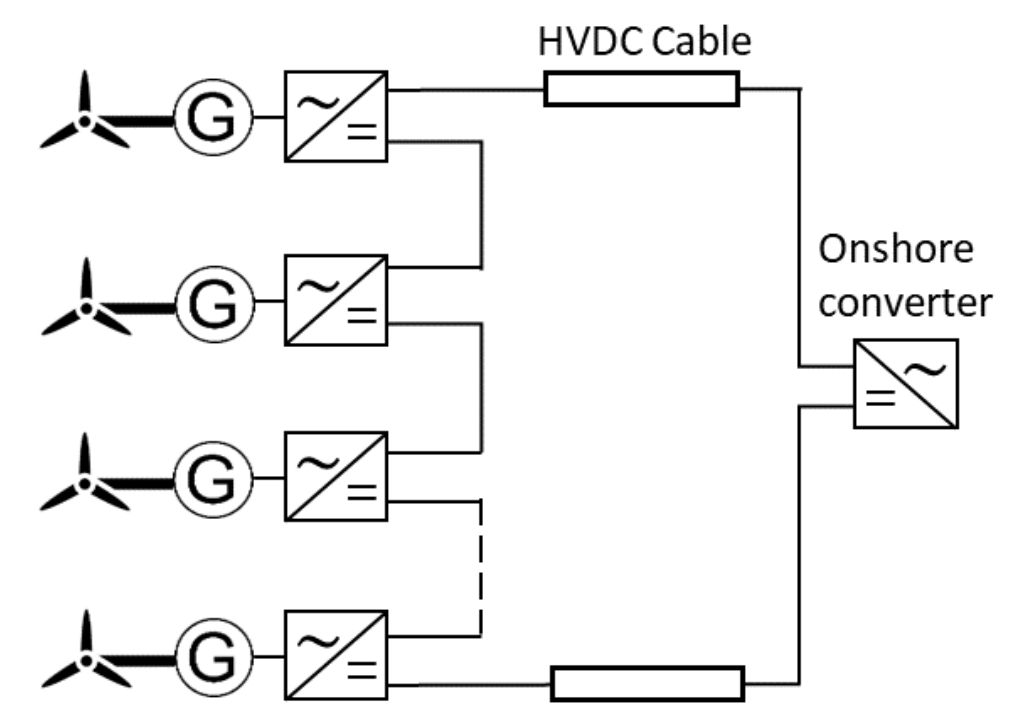

Figure 7. DC collection system with series-connected WTs.

Despite all WTs having the same voltage and current ratings, their insulation voltage requirement varies along the string: from generation levels, for the WTs closest to the grounding point, to transmission levels, for the WTs farthest from the grounding point [45].

The reduction of collection system losses is addressed by reference [46], which proposes an alternative series connection introducing a power sharing converter when the OWPP operates below nominal power, while reference [47] studied a series-connected layout which further reduces the number of offshore components. The latter proposes to control clusters of WTs to eliminate the use of a dedicated DC/DC converter for each WT. However, this method does not allow controling WTs individually to extract the maximum power.

\subsection{Hybrid Topologies}

Series-parallel (SP) topologies, depicted in Figure 8, was developed to mitigate the complexity of controlling the voltage of the DC collection system connected in series as a single string. It combines features of the parallel and series topologies, inheriting the advantages of the latter, such as the elimination of the offshore platform and lower connection costs [48]. The multiple parallel strings in this configuration increase the reliability of the WPP. In case of an internal fault, only the faulty string may trip, leaving the others in operation. However, the remaining WTs must increase their terminal voltage to compensate for the absence of the faulted WT. The resulting over-voltages may trip the protections of the healthy WTs, shutting down the entire string. Such issues may result in lower WPP efficiency and reliability, therefore, different over-voltage limitation methods were proposed in $[48,49]$. In this context, bypass protections are also essential to during an internal fault [48]. 


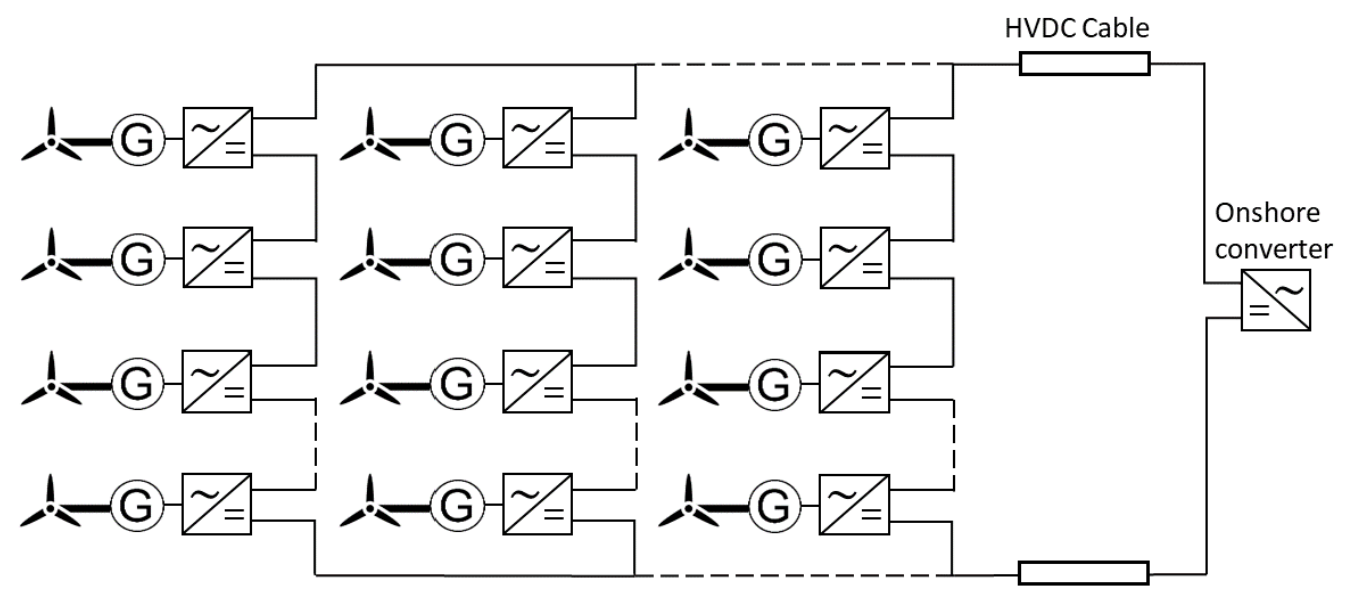

Figure 8. DC collection system with series-parallel-connected WTs.

However, SP topologies may still be sensitive to variations in output power among the series-connected WTs. Corresponding variations in the WT terminal voltages may lead to excessive stresses on the converter components. A solution for this issue was proposed in [50].

Matrix-interconnected (MI) topologies, illustrated in Figure 9, were proposed as solutions to achieve higher WPP efficiency and reliability [49,51]. MI topology is a type of series-parallel topology that feature switches between the strings to create auxiliary paths to reconfigure the strings and mitigate the over-voltages in the case of a faulted WT. The remaining, healthy WTs in the string, can thus be connected to an adjacent healthy string. This reduces the over-voltages in the healthy WTs and provides maximum available power for the OWPP. By focusing on current control, it is possible to reduce the collection system losses. However, this topology has drawbacks, such as the higher number of interconnections due to the required auxiliary switches, and the higher control complexity $[49,51]$.

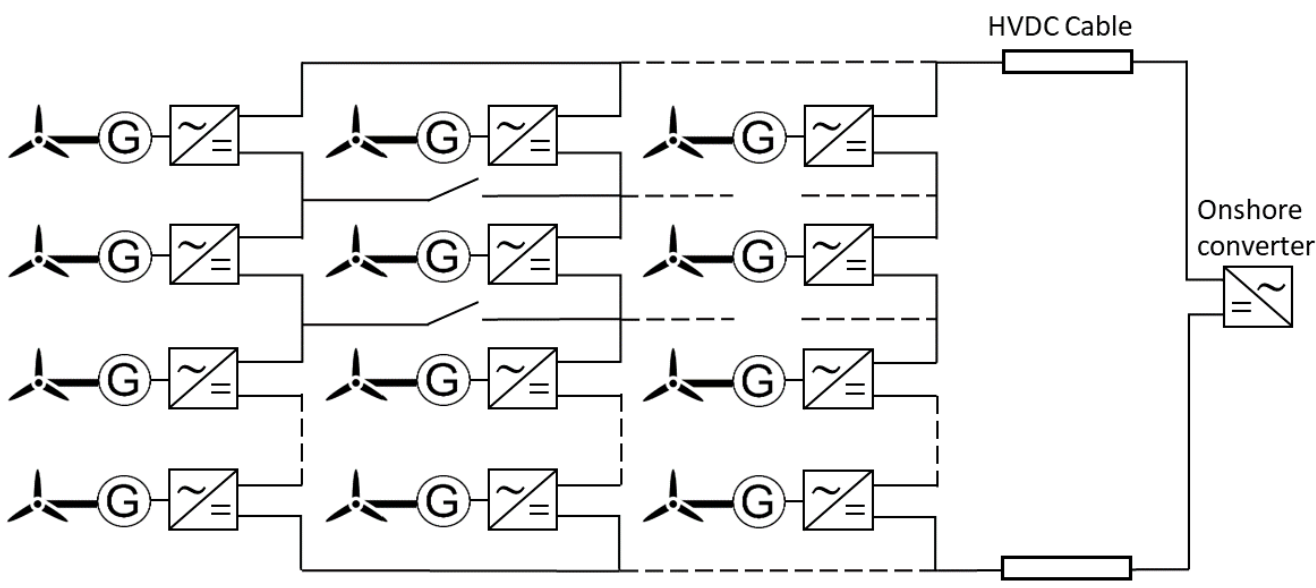

Figure 9. DC collection system with matrix-interconnected WTs.

A different approach to achieve higher reliability with series-parallel collection systems is to connect a large number of strings. This makes the collection system topology more similar to a parallel topology, thus reducing the benefits of the series topology [52].

Table 2 summarises the main advantages and disadvantages of the DC collection system topologies presented in this section. For each DC collection system topology, the main open issues and the corresponding proposed solutions are also highlighted. 
Table 2. Summary of DC collection system topologies.

\begin{tabular}{|c|c|c|c|c|}
\hline Layout & Advantages & Disadvantages & Relevant Open Issues & Methodologies \\
\hline $\begin{array}{l}\text { Parallel-Two } \\
\text { stages }\end{array}$ & $\begin{array}{l}\text { Lower collection cable losses and } \\
\text { redundancy in the WT control [10]. }\end{array}$ & $\begin{array}{l}\text { Increased losses and costs associated with the } \\
\text { additional DC/DC converters [10]. }\end{array}$ & $\begin{array}{l}\text { Relevant open issues for parallel-connected DC } \\
\text { OWPP are the same for parallel-connected AC } \\
\text { OWPP e.g., dynamic control of converters, } \\
\text { insulation requirements [40] and management of } \\
\text { faults inside the wind farm. }\end{array}$ & \\
\hline $\begin{array}{l}\text { Parallel-Single } \\
\text { centralised stage }\end{array}$ & $\begin{array}{l}\text { Minimal number of DC/DC } \\
\text { converters, higher overall efficiency. }\end{array}$ & $\begin{array}{l}\text { Lower voltage level in the collection system, } \\
\text { resulting in higher collection cable losses [10]. }\end{array}$ & $\begin{array}{l}\text { Parallel-connected DC OWPP needs to comply to } \\
\text { grid codes for OWPPs, which are currently } \\
\text { written in such way that they do not include } \\
\text { all-DC OWPPs }[13,14]\end{array}$ & \\
\hline $\begin{array}{l}\text { Parallel—Single } \\
\text { decentralised stage }\end{array}$ & $\begin{array}{l}\text { Low collection cable losses; no } \\
\text { offshore substation is required. }\end{array}$ & $\begin{array}{l}\text { Feasible only for close to shore OWPPs; Lower } \\
\text { efficiency for lower power ratings DC/DC } \\
\text { converters [10]. }\end{array}$ & & \\
\hline \multirow[t]{2}{*}{ Series } & $\begin{array}{l}\text { Less conversion stages, potentially } \\
\text { higher power plant efficiency; it } \\
\text { does not require an offshore } \\
\text { platform }[7,39] \text {. }\end{array}$ & $\begin{array}{l}\text { The voltage is not distributed uniformly among } \\
\text { the WTs in the string, since the wind does not } \\
\text { blow uniformly on the entire OWPP. }\end{array}$ & $\begin{array}{l}\text { Control of series-connected DC/DC } \\
\text { converters [40-43]. }\end{array}$ & $\begin{array}{l}\text { A voltage balance circuit to mitigate the } \\
\text { over-voltage [44] and an over-voltage limitation } \\
\text { strategy to ensure that the WTs are operating } \\
\text { within a safe limit [42] are proposed. }\end{array}$ \\
\hline & & $\begin{array}{l}\text { Insulation voltage requirements vary along the } \\
\text { string, from generation to transmission } \\
\text { levels [45]. }\end{array}$ & Increasing the efficiency of the OWPP [44]. & $\begin{array}{l}\text { The efficiency of the OWPP can be increased } \\
\text { e.g., choosing the most suitable converter } \\
\text { topology, the most appropriate modulation } \\
\text { technique [44] or adopting alternative series } \\
\text { connections to reduce the number of offshore } \\
\text { components }[46,47] \text {. }\end{array}$ \\
\hline \multirow[t]{2}{*}{ Series-parallel } & $\begin{array}{l}\text { Mitigates (partially) the complexity } \\
\text { of voltage control in } \\
\text { series-connected DC collection } \\
\text { system [48]. }\end{array}$ & $\begin{array}{l}\text { Requires remaining WTs to increase increase } \\
\text { terminal voltage [48]. }\end{array}$ & Over-voltages protection activation [48]. & $\begin{array}{l}\text { Alternative over-voltage limitation } \\
\text { methods }[48,50] \text {. }\end{array}$ \\
\hline & $\begin{array}{l}\text { In the case of fault, provides } \\
\text { redundancy [48]. }\end{array}$ & & $\begin{array}{l}\text { Sensitive to variations in power among the } \\
\text { series-connected WTs [50]. }\end{array}$ & $\begin{array}{l}\text { Variations in the WT terminal voltages may lead } \\
\text { to excessive stresses on the on the output } \\
\text { capacitors of the DC/DC converters [ } 50] \text {. }\end{array}$ \\
\hline $\begin{array}{l}\text { Matrix- } \\
\text { interconnected }\end{array}$ & $\begin{array}{l}\text { Reduces over-voltages and allows } \\
\text { maximum power for the } \\
\text { OWPP }[49,51] .\end{array}$ & $\begin{array}{l}\text { Higher number of interconnections due to } \\
\text { auxiliary switches; high control } \\
\text { complexity [49,51]. }\end{array}$ & & \\
\hline
\end{tabular}




\section{Challenge III: Grid Code Requirements}

Grid codes are technical specifications which define the set of rules an OWPP connected to the onshore grid has to meet to ensure safe and secure functioning of the onshore grid, both during normal and faulty conditions. This section discusses the possible changes to the current grid codes needed to the connection of all-DC OWPP to the onshore grid.

Grid codes are usually defined at the national level by the corresponding transmission system operators (TSOs). Recently, the European Commission asked the European Network of Transmission System Operators for Electricity (ENTSO-E) to unify the national grid codes across Europe. In 2016, the Network Code Requirements for Generators (NC RfG) [13] and the Network Code High Voltage Direct Current (NC HVDC) [14] came into force as European Commission Regulation. The two outputs from ENTSO-E act as a framework for individual TSO grid codes, leaving more detailed implementations of the connection requirements to the national grid codes.

Both the NC RfG and NC HVDC define requirements that must be met when connecting OWPPs to the onshore AC grids. The NC RfG applies only to AC-connected WPPs. The NC HVDC harmonises also the HVDC connection of OWPPs. Nevertheless, HVDC systems are defined as electrical power systems that transfer energy between two or more alternating current $(\mathrm{AC})$ buses. In this definition, it is thus clear that the current European grid codes were defined for AC OWPPs having an HVDC connection to shore. Worth highlighting is also the fact that such grid codes consider the HVDC connections between OWPPs and the onshore AC grids as transmission systems only. In future DC OWPPs, HVDC connections may however become constructive parts of DC OWPPs themselves, and corresponding interfaces (e.g., point of connection) may thus change.

Most of the current requirements seem compatible with future all-DC OWPPs. For example, both AC and DC large-scale OWPPs and corresponding transmission systems are required to stay connected during frequency changes in the onshore AC grids and modulate the active power output so as to contribute to maintain a stable frequency. When the onshore AC grids experience voltage (magnitude) deviations, OWPPs and corresponding transmission systems must also remain connected and provide support by injecting or absorbing reactive power. However, the reactive power control capability of all-DC OWPPs must be redefined. The existing OWPPs rely on AC collection systems and may thus meet the corresponding requirement in the NC HVDC, which defines the HVDC transmission system as having reactive power present at both its offshore and onshore ends. Future all-DC OWPPs will most likely be connected via HVDC transmission, but they will not be capable of controlling reactive power at the offshore end of their HVDC transmission systems, due to the nature of DC technology.

\section{Discussion}

Three challenges in the development of all-DC OWPPs were presented in the previous sections. In this section, some of the corresponding research gaps are highlighted.

At the component level, there are currently no standard topologies for MV DC/DC converters. At the same time, the reliability of such converters in the context of allDC OWPPs remains a topic open for discussion, since there are no operative full-scale pilots yet. However, it is worth noting that DC/DC converters are currently used in the railway industry and there were laboratory demonstrators for all-DC OWPPs [21]. Medium voltage levels can be reached in DC collection systems by connecting several DC/DC converters. DAB converters can be arranged in the so-called input-parallel-outputseries (IPOS) connection: in parallel at the low-voltage (input) side and in series at the high-voltage (output) side. However, the available literature focuses on case studies without giving general indications of the possible range of voltages that can be reached. Potential limitations due to the control complexity of the DAB converters at medium-high voltage levels need to be considered as well, when stacking several such devices. Another possibility to reach medium voltage level, would be to use HB or FB MMC converters. This 
kind of technology is proven at HVDC level, and it is a valid option to interface MVDC and HVDC systems.

At the system level, three main DC collection system topologies were presented, namely parallel, series, and hybrid. The parallel DC topologies are the most similar to conventional AC collection system topologies, which were extensively studied in recent decades. Therefore, there are currently not many research efforts devoted to the study of parallel DC topologies. On the other hand, series and hybrid topologies are specific to DC collection systems. Series topology is attractive for the possibility of avoiding the installation of offshore substations, which reduces costs without compromising the DC collection system efficiency. The main drawback of this topology is the control of the voltage within each string when power production varies among the connected generators. Substantial research has been conducted on this matter, but it remains an open challenge despite the different control algorithms proposed. Another challenge regards the insulation of DC/DC converters, which need to withstand possible large voltage variations due to the uneven power production along the string. The insulation also varies along the string, since the voltage builds up in the series connection of WTs. Hybrid topologies were proposed to mitigate some of the issues arising in the series topology. However, hybrid topologies rely on controls that are more elaborate than those devised for series topology, resulting in different control issues, which have not been fully addressed yet. Most studies have so far focused on the behaviour of DC/DC converters at a component level, while only few studies were conducted on interactions of such devices at the WPP level [53].

On a more general level, the existing grid codes should be revised so as to contemplate the connection of all-DC OWPPs. The production of electricity from DC WTs is currently not taken into account in [13]. For example, the application of the existing grid codes requires all OWPPs to be capable of injecting or absorbing a certain amount of reactive power at the offshore point of connection: a capability not suitable for DC systems. Furthermore, an HVDC transmission system is defined in [14] as a system connecting two AC systems, thus excluding all-DC OWPPs.

\section{Conclusions}

Three challenges to the development of all-DC OWPPs were highlighted in this paper, analysing their advantages and limitations. The challenges address different levels: from DC/DC converter topologies to their controls when arranged in different DC collection system topologies, to the existing grid codes. The identified current main research gaps are the maturity of DC/DC converter topologies for MV applications, the control issues in series and hybrid DC collection system topologies, and the adaptation of grid codes necessary to enable the connection of all-DC OWPPs to the onshore grids. Potential future directions were also proposed.

Author Contributions: Conceptualisation, visualisation and writing-review and editing: A.F., O.S.R., E.T. and N.A.C.; Funding acquisition: E.T. and N.A.C.; Supervision: O.S.-R., N.A.C. and E.T.; Methodology, project administration and writing—original draft preparation: A.F. All authors have read and agreed to the published version of the manuscript.

Funding: This research received no external funding.

Conflicts of Interest: The authors declare no conflict of interest. The funders had no role in the design of the study; in the collection, analyses, or interpretation of data; in the writing of the manuscript, or in the decision to publish the results.

\section{References}

1. IRENA. Global Energy Transformation: A Roadmap to 2050; Report; International Renewable Energy Agency: Abu Dhabi, United Arab Emirates, 2018.

2. IRENA. Future of Wind: Deployment, Investment, Technology, Grid Integration and Socio-Economic Aspects (A Global Energy Transformation Paper); Report; International Renewable Energy Agency: Abu Dhabi, United Arab Emirates, 2019.

3. IEA. Renewables 2019: Market Analysis and Forecast from 2019 to 2024; Report; International Energy Agency: Paris, France, 2019. 
4. Rodrigues, S.; Restrepo, C.; Kontos, E.; Teixeira Pinto, R.; Bauer, P. Trends of offshore wind projects. Renew. Sustain. Energy Rev. 2015, 49, 1114-1135. [CrossRef]

5. Lehmann, M.; Pieschel, M.; Juamparez, M.; Kabel, K.; Kocewiak, Ł.H.; Sahukari, S. Active Filtering in a Large-Scale STATCOM for the Integration of Offshore Wind Power. In Proceedings of the 17th Wind Integration Workshop, Stockholm, Sweden, 17-19 October 2018.

6. Pan, J.; Qi, L.; Li, J.; Reza, M.; Srivastava, K. DC Connection for Large-Scale Wind Farms. In Proceedings of the 9th Wind Integration Workshop, Quebec City, QC, Canada, 18-19 October 2010.

7. De Prada Gil, M.; Domínguez-García, J.L.; Díaz-González, F.; Aragüés-Peñalba, M.; Gomis-Bellmunt, O. Feasibility analysis of offshore wind power plants with DC collection grid. Renew. Energy 2015, 78, 467-477. [CrossRef]

8. Musasa, K.; Nwulu, N.I.; Gitau, M.N.; Bansal, R.C. Review on DC collection grids for offshore wind farms with high-voltage DC transmission system. IET Power Electron. 2017, 10, 2104-2115. [CrossRef]

9. Shao, S.J.; Agelidis, V.G. Review of DC System Technologies for Large Scale Integration of Wind Energy Systems with Electricity Grids. Energies 2010, 3, 1303-1319. [CrossRef]

10. Meyer, C.; Hoing, M.; Peterson, A.; De Doncker, R.W. Control and design of DC grids for offshore wind farms. IEEE Trans. Ind. Appl. 2007, 43, 1475-1482. [CrossRef]

11. Jovcic, D.; Hertem, D.V.; Linden, K.; Taisne, J.P.; Grieshaber, W. Feasibility of DC Transmission Networks. In Proceedings of the 2nd IEEE PES International Conference and Exhibition on Innovative Smart Grid Technologies, Manchester, UK, 5-7 December 2011; pp. 1-8. [CrossRef]

12. Robles, E.; Haro-Larrode, M.; Santos-Mugica, M.; Etxegarai, A.; Tedeschi, E. Comparative analysis of European grid codes relevant to offshore renewable energy installations. Renew. Sustain. Energy Rev. 2019, 102, 171-185. [CrossRef]

13. ENTSO-E. Network Code on Requirements for Grid Connection of Generators. Available online: https://eur-lex.europa.eu/ legal-content/EN/TXT/PDF/?uri=CELEX:32016R0631\&from=EN (accessed on 30 March 2021).

14. ENTSO-E. Network Code on Requirements for Grid Connection of High Voltage Direct Current Systems and Direct CurrentConnected Power Park Modules. Available online: https://eur-lex.europa.eu/legal-content/EN/TXT/PDF/?uri=CELEX: 32016R1447\&from=EN (accessed on 30 March 2021).

15. Deng, F.; Chen, Z. Operation and control of a DC-grid offshore wind farm under DC transmission system faults. IEEE Trans. Power Deliv. 2013, 28, 1356-1363. [CrossRef]

16. Max, L.; Lundberg, S. System efficiency of a DC/DC converter-based wind farm. Wind Energy Int. J. Prog. Appl. Wind Power Convers. Technol. 2008, 11, 109-120. [CrossRef]

17. Dincan, C.; Kjaer, P.; Chen, Y.H.; Nielsen, S.M.; Bak, C.L. Selection of DC/DC converter for offshore wind farms with MVDC power collection. In Proceedings of the 19th European Conference on Power Electronics and Applications (EPE'17 ECCE Europe), Warsaw, Poland, 11-14 September 2017; pp. P.1-P.10.

18. Zhou, Y.; Macpherson, D.; Blewitt, W.; Jovcic, D. Comparison of DC-DC converter topologies for offshore wind-farm application. In Proceedings of the 6th IET International Conference on Power Electronics, Machines and Drives (PEMD), Bristol, UK, 27-29 March 2012; pp. 1-6.

19. Musasa, K.; Gitau, M.N.; Bansal, R.C. Dynamic analysis of DC-DC converter internal to an offshore wind farm. IET Renew. Power Gener. 2015, 9, 542-548. [CrossRef]

20. Forouzesh, M.; Siwakoti, Y.P.; Gorji, S.A.; Blaabjerg, F.; Lehman, B. Step-Up DC - DC Converters : A Comprehensive Review of Voltage-Boosting Techniques. IEEE Trans. Power Electron. 2017, 32, 9143-9178. [CrossRef]

21. Dincan, C.G. High Power Medium Voltage DC/DC Converter Technology for DC Wind Turbines. Ph.D. Thesis, Aalborg University, Aalborg, Denmark, 2018.

22. Engel, S.P.; Stieneker, M.; Soltau, N.; Rabiee, S.; Stagge, H.; De Doncker, R.W. Comparison of the modular multilevel DC converter and the dual-active bridge converter for power conversion in HVDC and MVDC grids. IEEE Trans. Power Electron. 2014, 30, 124-137. [CrossRef]

23. Lagier, T.; Ladoux, P. A comparison of insulated DC-DC converters for HVDC off-shore wind farms. In Proceedings of the International Conference on Clean Electrical Power (ICCEP), Taormina, Italy, 16-18 June 2015; pp. 33-39.

24. Jimichi, T.; Kaymak, M.; De Doncker, R.W. Design and loss analysis of a medium-voltage DC-DC converter intended for offshore wind farms. In Proceedings of the IEEE International Conference on Renewable Energy Research and Applications (ICRERA), Birmingham, UK, 20-23 November 2016; Volume 5, pp. 137-142. [CrossRef]

25. Roggia, L.; Beltrame, F.; Schuch, L.; Pinheiro, J.R. Comparison between full-bridge-forward converter and DAB converter. In Proceedings of the Brazilian Power Electronics Conference, Gramado, Brazil, 27-31 October 2013; pp. $224-229$.

26. Soltau, N.; Stagge, H.; De Doncker, R.W.; Apeldoorn, O. Development and demonstration of a medium-voltage high-power DC-DC converter for DC distribution systems. In Proceedings of the 5th International Symposium on Power Electronics for Distributed Generation Systems (PEDG), Galway, Ireland, 24-27 June 2014; pp. 1-8. [CrossRef]

27. Soltau, N.; Lange, J.; Stieneker, M.; Stagge, H.; De Doncker, R.W. Ensuring Soft-Switching Operation of a Three-Phase Dual-Active Bridge DC-DC Converter applying an Auxiliary Resonant-Commutated Pole. In Proceedings of the 16th European Conference on Power Electronics and Applications (EPE-ECCE Europe), Lappeenranta, Finland, 26-28 August 2014.

28. Freijedo, F.D.; Rodriguez-Diaz, E.; Dujic, D. Stable and passive high-power dual active bridge converters interfacing MVDC grids. IEEE Trans. Ind. Electron. 2018, 65, 9561-9570. [CrossRef] 
29. Zeng, R.; Xu, L.; Yao, L.; Williams, B.W. Design and Operation of a Hybrid Modular Multilevel Converter. IEEE Trans. Power Electron. 2014, 30, 1137-1146. [CrossRef]

30. Akbar, A.; Far, J.; Hajian, M.; Jovcic, D.; Audichya, Y. High-power modular multilevel converter optimal design for DC / DC converter applications. IET Power Electron. 2016, 9, 247-255. [CrossRef]

31. Chang, Y.; Shi, G.; Zhang, J.; Cai, X. Analysis and Design of a MMC based Wind Power Converter for Offshore DC Grids. In Proceedings of the 41st Annual Conference of the IEEE Industrial Electronics Society (IECON), Yokohama, Japan, 9-12 November 2015; pp. 1363-1368. [CrossRef]

32. Kenzelmann, S.; Rufer, A.; Dujic, D.; Member, S.; Canales, F.; De Novaes, Y.R. Isolated DC/DC Structure Based on Modular Multilevel Converter. IEEE Trans. Power Electron. 2015, 30, 89-98. [CrossRef]

33. Liu, H.; Dahidah, M.; Naayagi, R.T.; Armstrong, M.; Yu, J. Unidirectional DC/DC modular multilevel converter for offshore wind farm with the control strategy based on stationary frame. J. Eng. 2019, 2019, 4309-4314. [CrossRef]

34. Carr, J.; Das, D.; Li, J.; Pan, J. Modular Multilevel Converter for Direct MVDC Connection of Offshore Wind Farms. In Proceedings of the IEEE Energy Conversion Congress and Exposition (ECCE), Montreal, QC, Canada, 20-24 September 2015; pp. 976-982. [CrossRef]

35. Abeynayake, G.; Li, G.; Liang, J.; Cutululis, N.A. A Review on MVdc Collection Systems for High-Power Offshore Wind Farms. In Proceedings of the 14th Conference on Industrial and Information Systems (ICIIS). Kandy, Sri Lanka, 18-20 December 2019; pp. 407-412. [CrossRef]

36. Bahirat, H.J.; Mork, B.A.; Høidalen, H.K. Comparison of wind farm topologies for offshore applications. In Proceedings of the IEEE Power and Energy Society General Meeting, San Diego, CA, USA, 22-26 July 2012; pp. 1-8.

37. Robinson, J.; Jovcic, D.; Joós, G. Analysis and design of an offshore wind farm using a MV DC grid. IEEE Trans. Power Deliv. 2010, 25, 2164-2173. [CrossRef]

38. Van Hertem, D.; Gomis-Bellmunt, O.; Liang, J. HVDC Grids for Transmission of Electrical Energy: Offshore Grids and a Future Supergrid; Chapter 6.3: DC OWPPs; Wiley-IEEE Press: New York, NY, USA, February 2016; pp. 1-481. [CrossRef]

39. Madariaga, A.; Martín, J.L.; Zamora, I.; Martínez De Alegría, I.; Ceballos, S. Technological trends in electric topologies for offshore wind power plants. Renew. Sustain. Energy Rev. 2013, 24, 32-44. [CrossRef]

40. Wang, Z.; Yao, L.; Wu, J.; Cai, X.; Shi, G. Large offshore wind power collection using DC grid technology. In Proceedings of the International Conference on Renewable Power Generation (RPG), Beijing, China, 17-18 October 2015; p. 6. [CrossRef]

41. Liserre, M.; Cardenas, R.; Molinas, M.; Rodriguez, J. Overview of multi-MW wind turbines and wind parks. IEEE Trans. Ind. Electron. 2011, 58, 1081-1095. [CrossRef]

42. Zhang, H.; Florez, D.; Saudemont, C.; Gruson, F. Control strategies of a dc based offshore wind farm with series connected collection grid. In Proceedings of the IEEE International Energy Conference (ENERGYCON), Leuven, Belgium, 4-8 April 2016; pp. 1-6.

43. Pan, J.; Bala, S.; Callavik, M.; Sandeberg, P. Platformless DC collection and transmission for offshore wind. In Proceedings of the 11th IET International Conference on AC and DC Power Transmission, Birmingham, UK, 10-12 February 2015; pp. 1-6. [CrossRef]

44. Rong, F.; Wu, G.; Li, X.; Huang, S.; Zhou, B. All-DC offshore wind farm with series-connected wind turbines to overcome unequal wind speeds. IEEE Trans. Power Electron. 2018, 34, 1370-1381. [CrossRef]

45. Withanage, R.; Crookes, W.; Shammas, N. Novel voltage balancing technique for series connection of IGBTs. In Proceedings of the European Conference on Power Electronics and Applications, Aalborg, Denmark, 2-5 September 2007; pp. 1-10.

46. Daniel, M.T.; Enjeti, P.N. A power sharing scheme for series connected offshore wind turbines in a medium voltage DC collection grid. In Proceedings of the IEEE Applied Power Electronics Conference and Exposition (APEC), Long Beach, CA, USA, 20-24 March 2016; pp. 1695-1701. [CrossRef]

47. Jovcic, D.; Strachan, N. Offshore wind farm with centralised power conversion and DC interconnection. IET Gener. Transm. Distrib. 2009, 3, 586-595. [CrossRef]

48. Zhang, H.; Gruson, F.; Rodriguez, D.M.F.; Saudemont, C. Overvoltage limitation method of an offshore wind farm with DC series-parallel collection grid. IEEE Trans. Sustain. Energy 2019, 10, 204-213. [CrossRef]

49. Chuangpishit, S.; Tabesh, A.; Moradi-Shahrbabak, Z.; Saeedifard, M. Topology Design for Collector Systems of Offshore Wind Farms With Pure DC Power Systems. IEEE Trans. Ind. Electron. 2014, 61, 320-328. [CrossRef]

50. Bahirat, H.J.; Mork, B.A.; Member, S. Operation of DC Series-Parallel Connected Offshore Wind Farm. IEEE Trans. Sustain. Energy 2019, 10, 596-603. [CrossRef]

51. Chuangpishet, S.; Tabesh, A. Matrix interconnected topology for dc collector systems of offshore wind farms. In Proceedings of the IET Conference on Renewable Power Generation (RPG), Edinburgh, UK, 6-8 September 2011; p. 1-4. [CrossRef]

52. Huang, Q.; Wang, X.; Qian, T.; Yao, L.; Wang, Y. Reliability assessment of DC series-parallel offshore wind farms. J. Eng. 2018, 2019, 1457-1461. [CrossRef]

53. Guan, M. A Series-Connected Offshore Wind Farm Based on Modular Dual-Active-Bridge (DAB) Isolated DC-DC Converter. IEEE Trans. Energy Convers. 2019, 34, 1422-1431. [CrossRef] 